\title{
ANALYSIS OF DYNAMIC LOADS OF THE ARMOURED PERSONNEL CARRIER CREW DURING FRONTAL CRASH
}

\author{
Zdzisław Hryciów \\ Military University of Technology \\ Kaliskiego Street 2, 00-908 Warszawa, Poland \\ tel.: +4822 6837403, fax.: +48226837370 \\ e-mail: zhryciow@wat.edu.pl
}

\begin{abstract}
The work describes chosen problem connected with using of armoured personnel carriers (APC) in the frame of stabilisation and peacekeeping mission. The new type of tasks appears: ramming obstacles such as fences, entry gates, light engineering obstacles and also pushing other vehicles aside the road in order to obtain trafficability. The main threat in such situation is a risk of serious injury of soldiers inside vehicle. The lack of a crumple zone increases a value of acceleration acting on the crew. In the work models of driver and crew member seats used in the APC were showed. To the tests a Hybrid III 50th male dummy model in a seated position were used, which is a good representation of the average population of men. To the modelling LS-DYNA software was applied. The work shows the numeric test results. Behaviour of the dummies during the impact on both the driver and crew member were presented. To assess a risk of injury standard indicators of crash test were used, including: maximum value of the head acceleration, the criterion HIC and the maximum values of the forces and moments in the neck. The distributions of these parameters were presented. Results of simulation indicated that velocity and location of dummies has large influence on levels of dynamic loads. To further research is proposed to take into consideration models of dummy with additional equipment of soldiers (e.g. a helmet, a weapon, a bullet-proof jacket).
\end{abstract}

Keywords: armoured personnel carrier, impact, passive safety, dummy, FE analysis

\section{Introduction}

The procedure for use the armed forces changes continuously. Besides conducting operations in classic military conflicts, the armed forces are used increasingly to carry out the preventive tasks in the framework of the multinational stabilisation and peacekeeping mission. Conditions of the mission causes that armoured personnel carrier (APC) are mainly used. The requirements of tactic and technical characteristics assume that this type of vehicles should ensure rapid movement of infantry along the roads as well as off-road driving and provide effective protection against bullet. Along with the change of the concept of the use of troops the constant change in armour and military equipment must be done simultaneously to meet required standards. The new type of tasks include ramming the different obstacles such as fences, entry gates, light engineering obstacles (barbed or concertina wire, barricades) and also pushing other vehicles aside the road in order to obtain trafficability. A significant slope of roads as well as reduced the effectiveness of the braking system caused by high temperature and significant growth of the vehicle weight (about $125 \%$ of vehicle operating in the country) increases braking distance. As a result, there are also cases of collision one vehicle to another in a column. During the preliminary analysis [3, 8], it was found that the serious limitation of the possibilities of ramming is not the structure of the vehicle, but the risk of crew injury, due to the high level of dynamic forces acting during the crash. Unlike cars, in which a crumple zone absorbs a large part of the impact energy, in the military vehicles which design is based on a rigid frame or integral body, there are no technical solutions to mitigate the effects of a crash. The fact should be taken into account that into a typical APC besides the driver and vehicle commander, additionally approximately eight troops are located. Due to the need of quickly exit the carrier through the rear doors, soldiers' seats are placed along the walls of 
the vehicle perpendicular to the direction of motion. Moreover, the only element of safety is lap seatbelts, which in frontal-impact situation are not able to protect the passengers effectively.

The main aim of the work was to determine the level of dynamic loads acting on the crew members during a frontal crash of carrier.

\section{Test object model}

The simulation tests were conducted on the basis of the model of eight-wheel armoured personnel carrier Rosomak. Description of the model is shown among others in the work [2]. In order to assess the exposure of the crew members on dynamic load, it was necessary to complete that model in elements having direct contact with soldiers in the vehicle - integrated driver seat and crew member seat together with the dummy. To the tests a Hybrid III 50th male dummy model in a seated position were used, which is a good representation of the average population of men. Applied model was developed and verified by the Livermore Software Technology Corporation [5,6], a manufacturer of software LS-DYNA. The applied dummies are equipped with sensors that allow specifying the acceleration and forces in parts of the body which are important form the human life threat point of view. This type of dummy is commonly used in numerical researches of cars crash test, however for military applications it is mainly used to assess occupant injury caused by mine blasts $[1,5,7,9]$. In the carrier Rosomak the only safety equipment are lap seatbelts. Therefore, the dummies on a driver and a crew member seats were fastened in such manner. On the Fig. 1 the location of the dummies inside the carrier are presented.
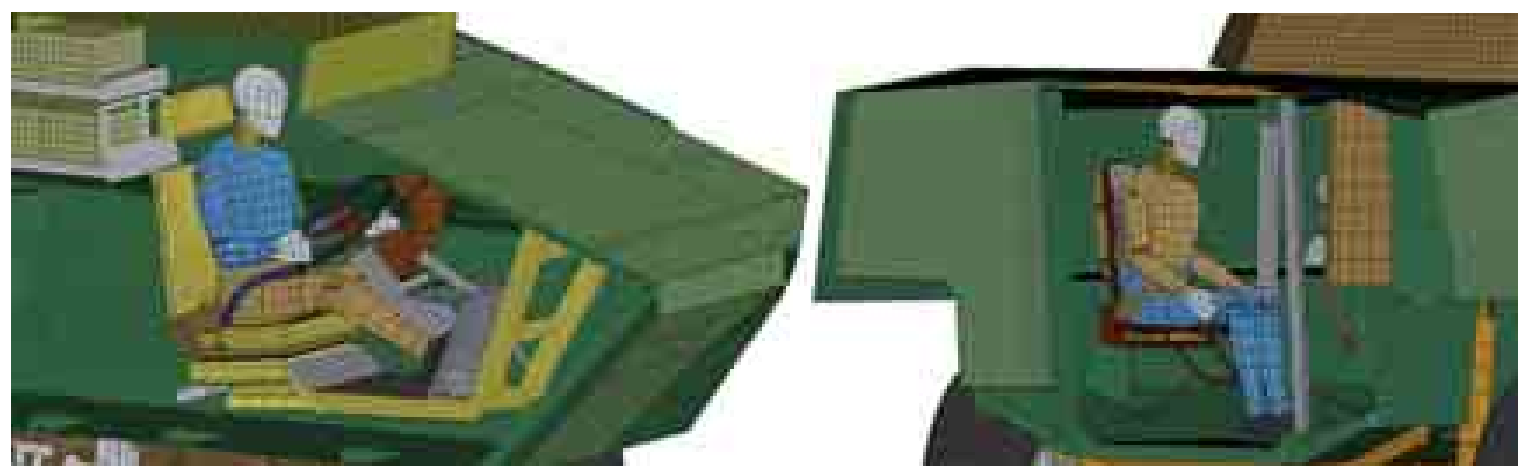

Fig. 1. The location of dummies inside a carrier: driver (left), crew member (right)

In order to assess the effects of impact velocity and dummies' positions on their behaviour and acting dynamic loads, during numerical simulation displacements, velocities and accelerations were computed as well as the following criterion [4]:

a) HIC (Head Injury Criterion) is defined as the maximum value of the time integration of the function a(t) in the interval $t_{1}$ to $t_{2}(1)$

$$
H I C=\max \left(\left(t_{2}-t_{1}\right) \cdot\left[\frac{1}{t_{2}-t_{1}} \int_{t_{1}}^{t_{2}} a(t) d t\right]^{2.5}\right),
$$

where:

$a(t) \quad-$ resultant head acceleration in $\mathrm{g}\left(1 \mathrm{~g}=9.81 \mathrm{~m} / \mathrm{s}^{2}\right)$,

$\left(t_{2}-t_{1}\right)-$ is an interval of time $36 \mathrm{~ms}$, for which the calculated index of HIC reaches maximum value,

The HIC value should not exceed 1000. Values above this level mean a serious threat to life for the occupants in the vehicle.

b) the maximum value of the resultant acceleration of the head $a_{h}[g]$,

c) the maximum value of the tension force $F_{z}[N]$, shear force $F_{x}[N]$ and bending moment $M_{y}$

$[\mathrm{Nm}]$ of dummy neck. 


\section{Numerical tests results}

The main purpose of the work was to determine the level of dynamic load of carrier crew members during frontal crash. To the tests two kinds of obstacles were used. The first one was a steel gate and the second one was a rigid wall. Numerical researches were conducted for the four cases:

a) case 1 - ramming a steel gate with initial velocity of $10 \mathrm{~m} / \mathrm{s}$,

b) case $2-4-$ collision with a rigid barrier with initial velocity of carrier respectively $v=6,3$, and $1.5 \mathrm{~m} / \mathrm{s}$.

In the first scenario, the vehicle overruns the gate and as a result it decreased its speed of about $3 \mathrm{~m} / \mathrm{s}$, however, the carrier was not stopped. In other cases the carrier was stopped and next was slightly rebounded from obstacles. In all cases displacements of the dummies was analysed and evaluation criterions were computed. The calculations were carried out in the LS-DYNA system.

On the Fig. 2. the displacement of the dummy on the driver seat at selected moments of time was presented. The results were calculated for the second case $(\mathrm{v}=6 \mathrm{~m} / \mathrm{s})$. Due to a lack of shoulder belt, the torso of the dummy is not held. As a result, for this initial velocity of impact, a dummy head hit the housing of the ventilation system which is made of plastic. In this moment a severe deflection of the head to the back has been observed, which results in the generation of large forces in the upper neck.

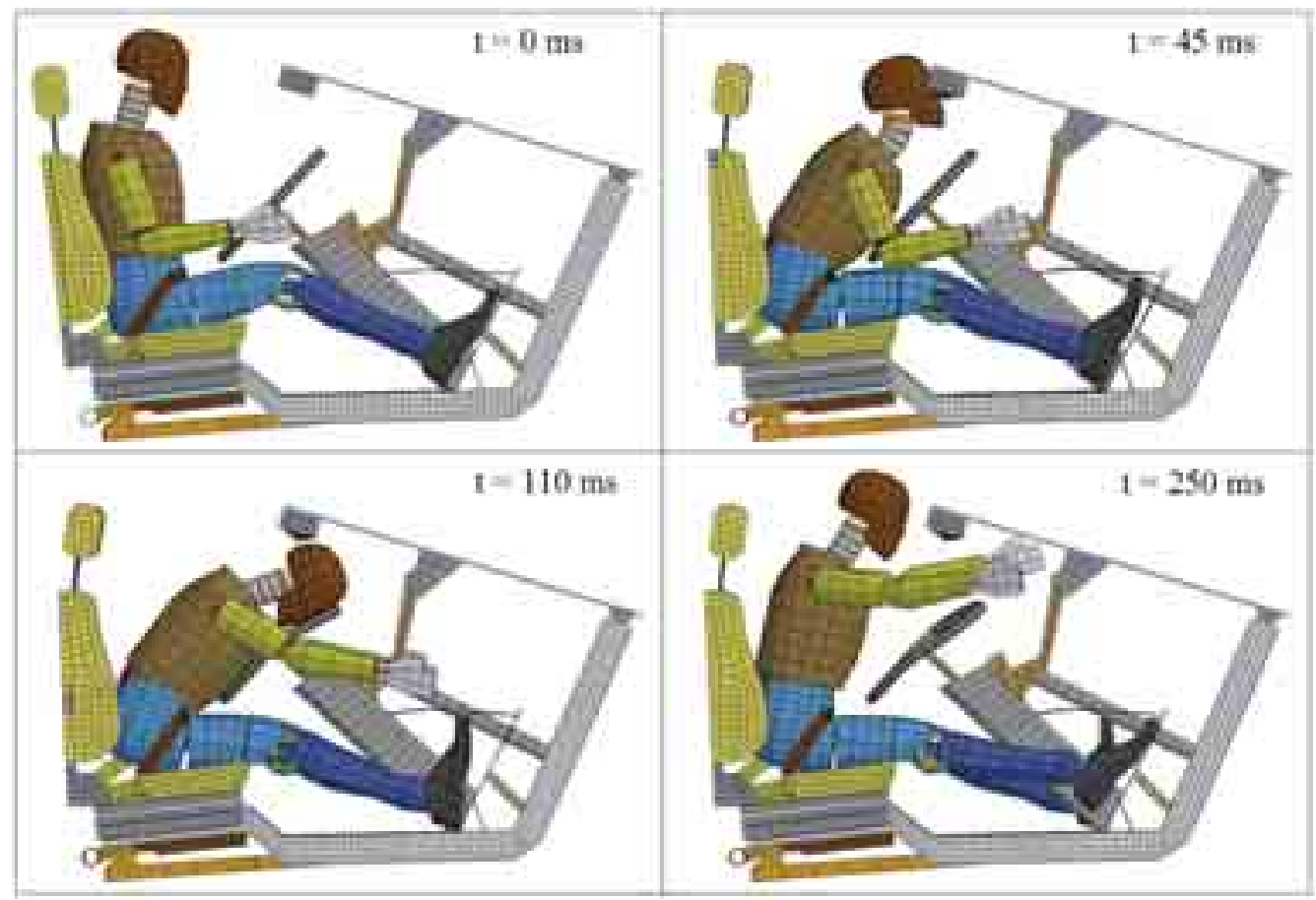

Fig. 2. Displacement of the dummy on the driver seat (case 2)

After partial destruction of ventilation housing, the further movement of the dummy occurs and finally his body and head hit the steering wheel. From this moment, the dummy body move back. For case 1 and 3, the head of the dummy hit the housing without its destruction and from this moment the dummy body move back. For case $4(\mathrm{v}=1.5 \mathrm{~m} / \mathrm{s})$ there is no head contact with elements of the vehicle equipment.

Figure 3. shows behaviour of the dummy on the crew member's seat to the same case. Due to the lateral position relative to the direction of movement, after impact, the movement of the dummy on the left occurs. The lap belt causes that the lumbar are held whereas the dummy torso rotate and slant to the front simultaneously. A strong deflection of the head to the left has been observed and the left arm is rejected in the side. After reaching the maximum deflection, the dummy body moves back. For other cases, movement of the dummy is similar, but smaller values of displacements were received. 


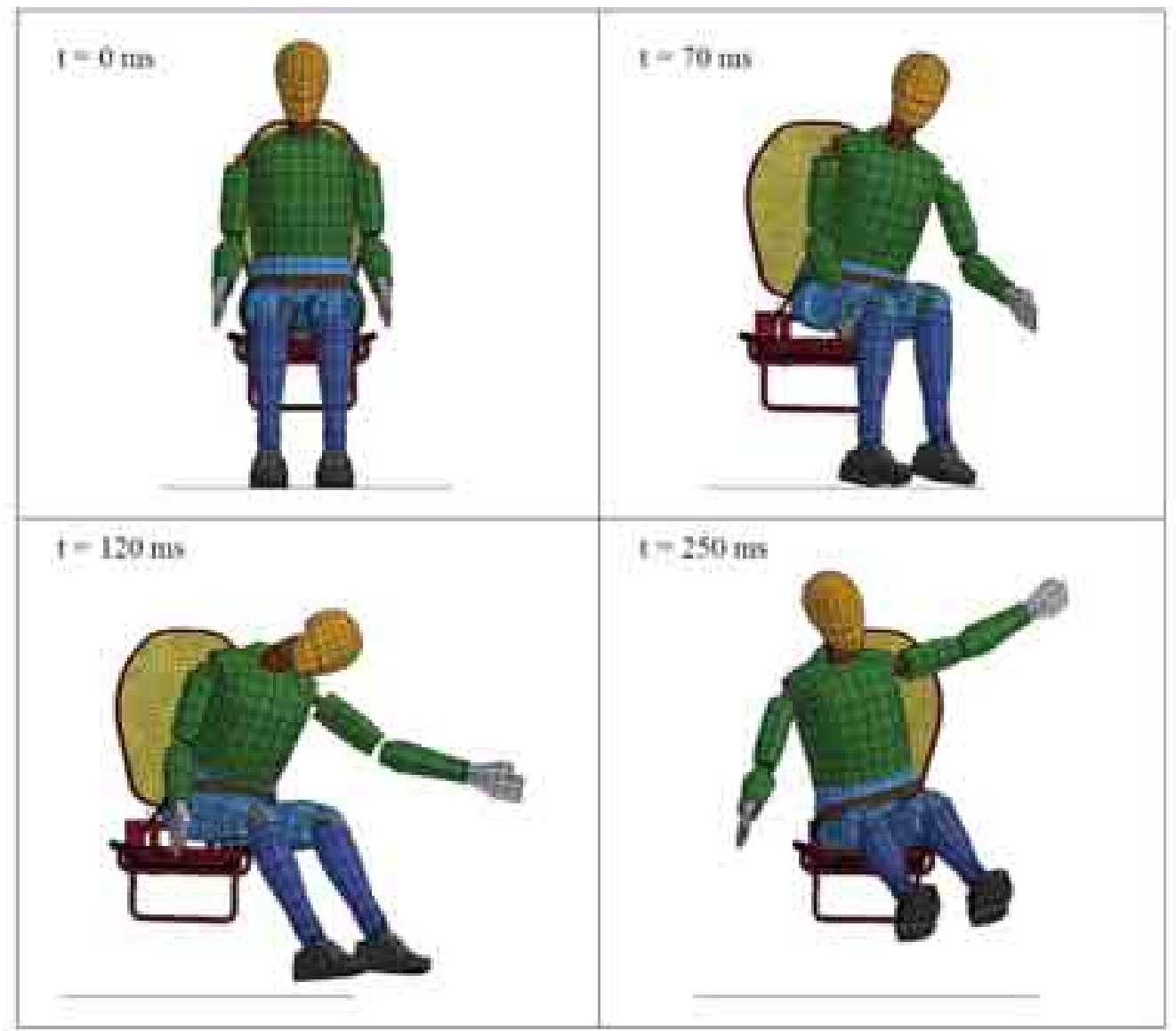

Fig. 3. Displacement of the dummy on the crew member's seat (case 2)

In order to determine the level of occupant injury risk the maximum values of the head acceleration $a_{h}$ were quantified (Fig. 4) and a HIC index was computed (Fig. 5). The maximum head acceleration appeared for case 2 for the driver of the vehicle. At the moment of head impact to the ventilation housing it reached $62 \mathrm{~g}$. However, it does not exceed the limit value specified in the [4] (88g for drivers with no steering wheel airbag). For case 1 and 3 accelerations $\mathrm{a}_{\mathrm{h}}$ are about $50 \%$ less. On the basis of the results presented on Fig. 4. it can be concluded that the maximum acceleration of the head of the crew members about $25-35 \%$ smaller than the drivers. This is due to the lack of head contact with elements of the carrier equipment.

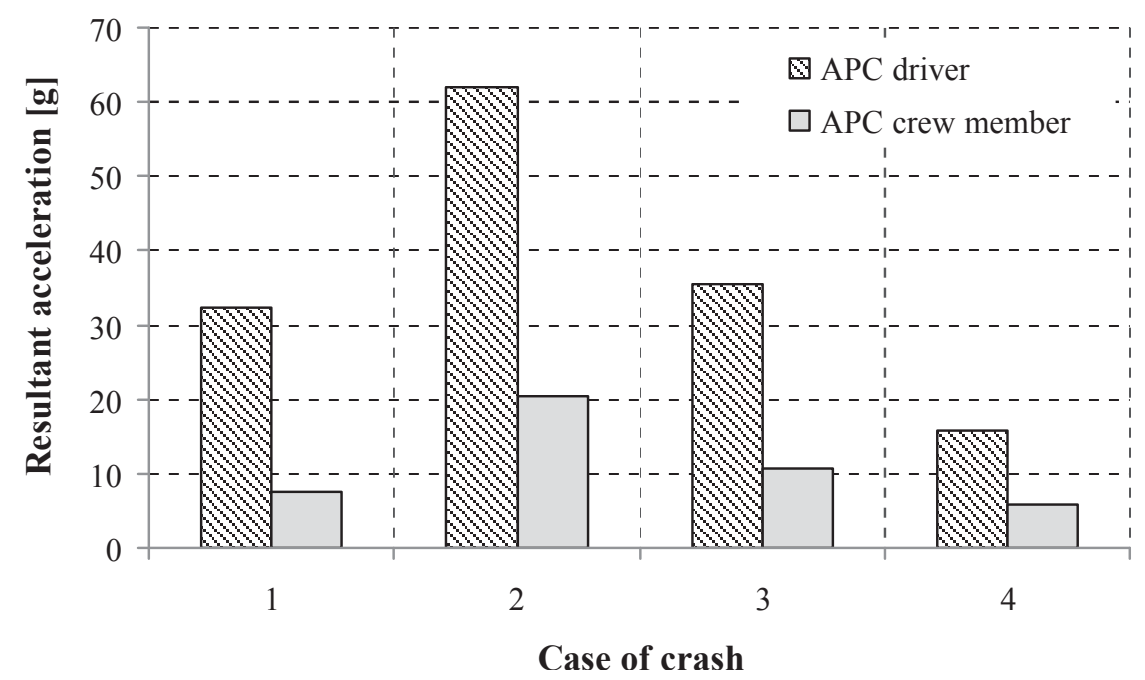

Fig. 4. The maximum values of resultant head acceleration 
The maximum value of the HIC index occurred for case 2 as well. It amounted to 92. So a small value of index compared to large values of maximum accelerations is caused by a short time of appearance of extreme values of accelerations.

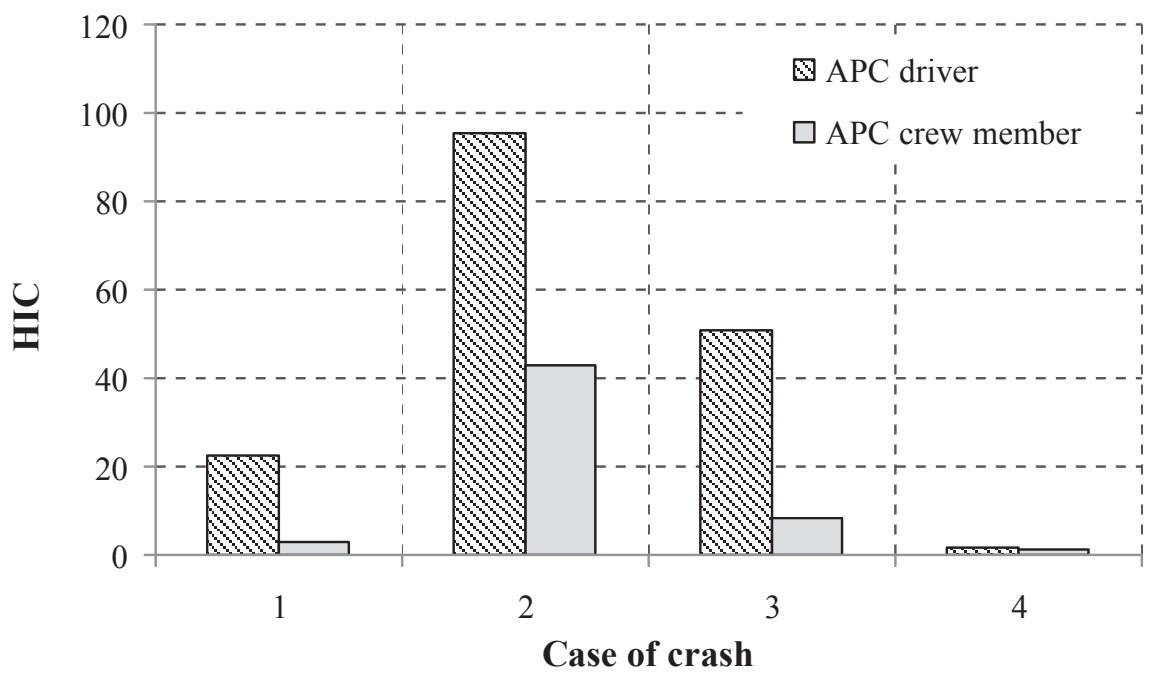

Fig. 5. The distribution of Head Injury Criterion

Important, from the point of view of exposure to injuries during the impact, are maximum values of forces and moments acting on neck. Fig. 6. shows the maximum values of upper neck tension force. The highest values were occurred for case 2 and the smallest for case 1. Permissible values of forces are dependent on their duration. A performance limit for human body is defined in [4]. Regarding very short time when maximum values of tension force appear (e.g. $3 \mathrm{~ms}$ for $1880 \mathrm{~N}$ ), the limit values were not exceeded. As the acceleration, the values of neck tension forces for crew member dummies were smaller, too.

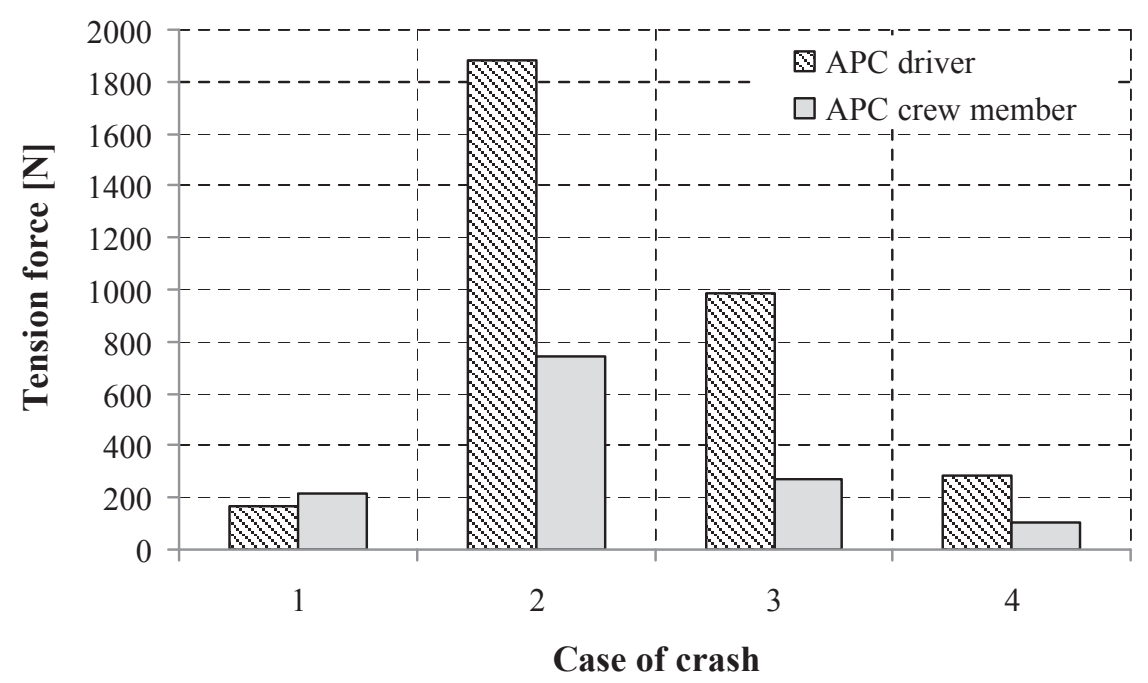

Fig. 6. The distribution of upper neck tension forces

On the Fig. 7. the maximum values of neck shear forces are presented. Their distribution for analysed cases is similar to tension forces. However, unlike the previous forces, the significant difference between driver and crew members shear forces was not occurred. Nevertheless, it should be pointed that the maximum shear force the driver neck acted in a longitudinal direction while for the crew - in the transverse direction (in dummy local coordinate system). The performance limits [4] have not been exceeded in any of the cases. 


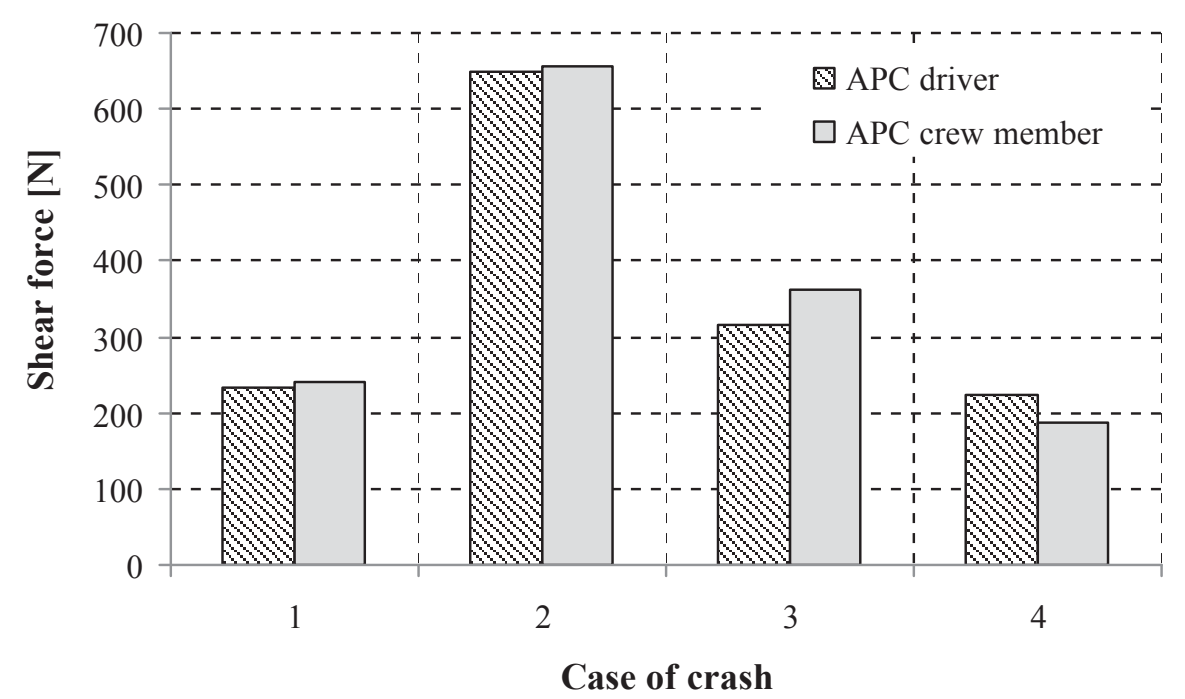

Fig. 7. The distribution of upper neck shear forces

On the Fig. 8. the maximum values of neck flexion bending moment are showed for all analysed cases. The maximum value of $37 \mathrm{Nm}$ is reached for case 2 . In the case of the dummy on crew member seat, obtained results of flexion moments for case 2 and $3(\mathrm{v}=6$ and $3 \mathrm{~m} / \mathrm{s}$ ) are almost the same. This is due to perpendicular location of dummy to the direction of carrier motion.

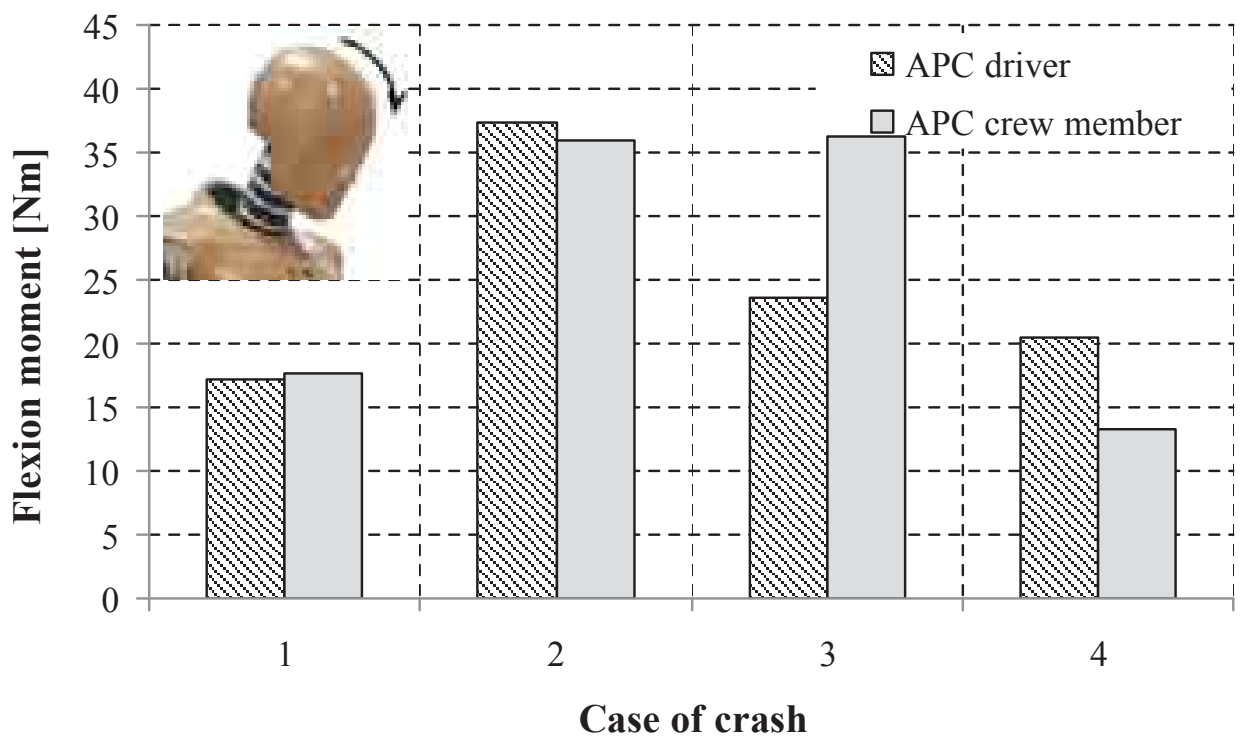

Fig. 8. The distribution of neck flexion bending moment

On the Fig. 9. the maximum values of neck extension bending moment are presented. The maximum value for case 2 occurred at the moment of impact of the head to ventilation housing. It reached $88 \mathrm{Nm}$ and exceeded the capping limit (57 Nm [4]). Overrunning this limit means a high probability of significant risk of injury.

\section{Summary}

Presented results of numerical tests helped to determine the risk injury level of APC crew members during collision with a rigid barrier and a steel gate. Due to the largest deceleration of the hull of the carrier the most dangerous appeared the case of collision with a barrier at initial velocity of $6 \mathrm{~m} / \mathrm{s}$. Received results confirmed the significant influence of vehicle velocity on the level of dynamic loads acting on the crew. The highest speed had a carrier during ramming a gate. 
However, due to plastic deformation of gate and its partial destruction, mild decrease of vehicle velocity has been observed, and as a result value of deceleration was smaller than during collision with barrier at a speed of 6 and $3 \mathrm{~m} / \mathrm{s}$.

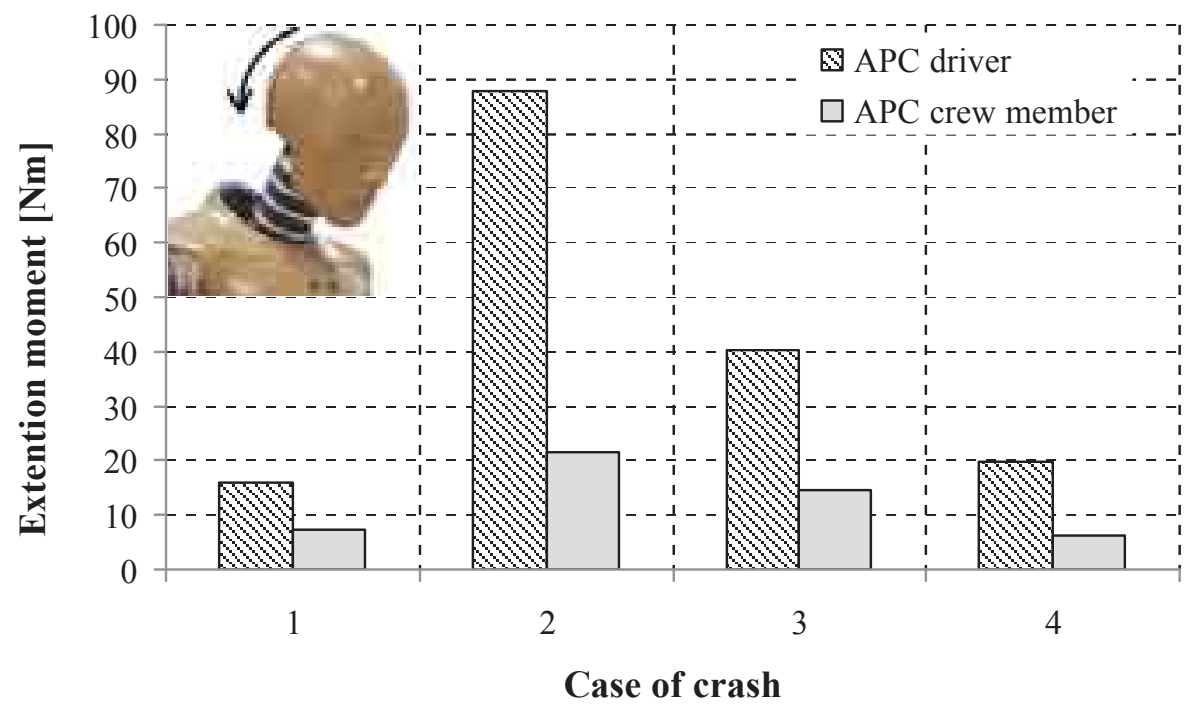

Fig. 9. The distribution of neck extension bending moment

In the framework, the analysis was limited only to the dummies without equipment. Real soldiers in the vehicle have individual equipment which possesses significant mass. It may include among others bullet-proof jacket, weapons and especially helmet. It can substantially affect the loads acting on the head. In addition, in rear compartment are located eight troops, who are from each other in close proximity. In some cases, there may occur hitting soldiers on themselves as well as their striking the seats of adjacent soldiers. For this reason, it seems advisable to widen the analysis of the above-mentioned aspects.

\section{Acknowledgement}

The scientific work financed by the funds assigned for the science in years 2010-2013 as a research project.

\section{References}

[1] Brill, A., Cohen, B., Du Bois, P. A., Simulation of a mine blast effect on the occupants of an $A P C$, 6th European LS-DYNA Users' Conference, pp. 4.155-4.166, Gothenburg 2007.

[2] Borkowski, W., Hryciów, Z., Rybak, P., Wysocki J., Badanie skutków oddziaływania tadunków wybuchowych na konstrukcje transportera opancerzonego, SYSTEMS Journal of Transdisciplinary Systems Science, Vol. 16, pp. 99-108, Wrocław 2012.

[3] Borkowski, W., Hryciów, Z., Preliminary investigation of dynamic loads of the crew of the armored personnel carrier during frontal crash, Journal of KONES Powertrain and Transport Vol. 15, No. 4, pp. 57-62, Warsaw 2008.

[4] European New Car Assessment Programme (Euro NCAP). Assessment protocol - adult occupant protection. Version 5.2, June 2010.

[5] Guha, S., Bhalsod, D., Krebs, J., LSTC Hybrid III Dummies. Positioning \& Post - Processing. Dummy Version: LSTC.H3.103008_v1.0, Livemore Software Technology Corporation Michigan 2008.

[6] Hallquist, J., O., LS-DYNA Keyword User's Manual.VolumeI. Version 971 R6.0.0, Livemore Software Technology Corporation, Livermore 2012. 
[7] Nilakantan, G., Tabiei, A., Computational Assessment of Occupant Injury Caused by Mine Blasts underneath Infantry Vehicles, International Journal of Vehicle Structures \& Systems 1(1-3), pp. 50-58, 2009.

[8] Orłowski, L., Pędzisz, M., Rzymkowski, C., Wyniki wstępnych badań eksperymentalnych oraz komputerowej symulacji zagrożenia osób $w$ trakcie uderzenia $w$ przeszkodę wojskowego samochodu terenowego, Journal of KONES Powertrain and Transport, Vol. 14, No. 3, pp. 495-502, Warsaw 2007.

[9] Panowicz, R., Sybilski, K., Kołodziejczyk, D., Niezgoda, T., Barnat, W., Numerical analysis of effects of IED side explosion on crew of lightarmoured wheeled vehicle, Journal of KONES Powertrain and Transport, Vol. 18, No. 4, pp. 331- 339, Warsaw 2011. 